Article

\title{
Numerical Simulation of the Protective Effect of an Anti-Uplift Protector on Subway Tunnels with Different Sections
}

\author{
Aiyuan Zheng \\ Shenzhen Metro CO., LTD, Shenzhen 518026, China; hssdu@163.com \\ Received: 12 November 2018; Accepted: 14 December 2018; Published: 27 December 2018
}

\begin{abstract}
The construction areas of both the upper water gallery of the left circular tunnel and the water gallery of the right square tunnel in the Shuangjie River gallery project in Shenzhen that pass through the parking access line of the Qianhai parking lot were numerically simulated. The ABAQUS finite element numerical simulation software was used to analyze the stress and strain of the cover and retaining pile with different sections under the design of tunnel anti-uplift protection measures. The results of the study are summarized as follows: The vertical deformation of the upper cover of the square section of tunnel was larger than that of the circular tunnel. The shear strength of the retaining pile on both sides of the square section tunnel was considerably lower than that of the retaining pile on both sides of the circular tunnel. The anti-uplift protection measures of the designed tunnel exhibited evident protective effects on the square and circular sections. However, the protection effect for the circular tunnel was more evident compared with that of the square section.
\end{abstract}

Keywords: subway tunnel; pile enclosure structure; covered plate; section form; anti-uplift

\section{Introduction}

Underground traffic systems in cities, particularly subway tunnels, are being increasingly developed [1-3]. Subway tunnels are commonly built under existing structures [4-8]. The development of subway tunnels has inevitably resulted in the construction of metro tunnels and various engineering structures [9-11]. For example, industrial and civil buildings are often built in the upper parts of a subway, and excavations are conducted near subways when constructing various structures [12]. The influence of engineering construction activities on the upper part of existing subway tunnels should be investigated. Engineering activities in the upper part of subway tunnels can be defined as loading and unloading processes of soil in the upper part of subway tunnels [13]. These loading and unloading processes of soil in the upper part of subway tunnels have different effects on subway tunnels with varying cross-sections [14-17].

Many scholars have carried out research on the mechanics of newly built tunnels passing under existing structures. Ratan Dasa [17] conducted a numerical simulation of a shallowly-buried, two-way, asymmetric tunnel in India, and studied the ground settlement and formation stability problems that may be caused by the subterranean construction. Wan [18] used Beijing Metro Line 7, which passes under the existing Shuanging Station on Line 10, as a case study. The construction of Line 7 was carried out using different construction methods, such as the full-section method, the bench method and the CRD method. The deformation and stress of the existing structure under different excavation modes were analyzed according to the simulation results, and the specific parameters of the auxiliary method were simulated to further determine the suitable reinforcement range and reinforcement length. Fang and Kenneally [19] conducted similar experimental studies on an expressway tunnel underpass under a coal mine. Their test focused on the influence of the distance between the tunnel and the dislocation 
interfaces and dip of the inclined coal seam.Zheng, $\mathrm{Y}$ and Qiu, $\mathrm{W}$ and others studied the section of the Changchun Light Rail that passes under a section of railway. The centrifuge of the subgrade settlement caused by the construction was studied using a model of water injection and waterproofing to simulate the formation loss caused by the tunnel construction.

This study analyzes the impact of the anti-uplift protection measures of metro tunnels on the protection effect for different tunnels within the Shuangjie River gallery project in Shenzhen. ABAQUS was used to simulate the unloading conditions in the upper section of the subway tunnels with different sections.

\section{Project Overview}

\subsection{Engineering Background}

This study is based on the Shuangie River water gallery project in Shenzhen, and the specific layout planning of the project is shown in Figure 1. The project mainly aims to transfer the main channel of the existing double-boundary river toward the south by $35 \mathrm{~m}$. The water gallery will intersect with the Qianhai car access road after the transfer, as shown in Figure 2.



Figure 1. Layout of the main channel of the waterway.

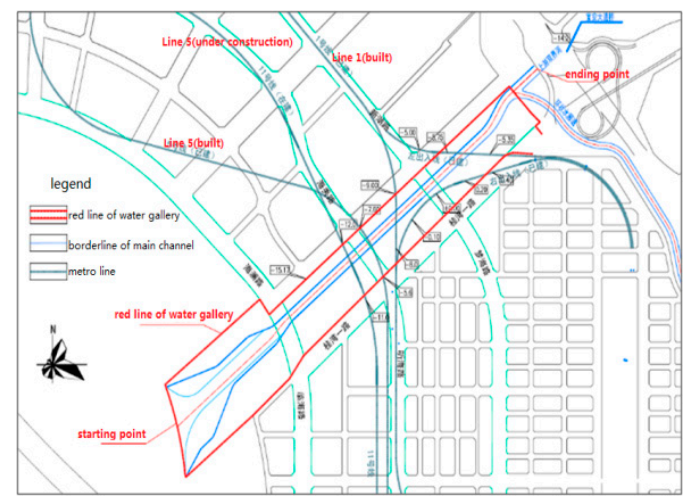

Figure 2. Relationship between waterways and subway lines.

\subsection{Metro Protection Program}

The excavation project adopts a staged construction method with a length of $10 \mathrm{~m}$. The first excavation of the ground elevation control is above an elevation of $1.0 \mathrm{~m}$ (within $5 \mathrm{~m}$ ), which forms a temporary construction platform. Bored piles (the pile top elevation is approximately $-2.0 \mathrm{~m}$ ) are set on both sides of the tunnel (with a $3.5 \mathrm{~m}$ interval). The diameter of a pile is $1.2 \mathrm{~m}$, and its spacing is 3-4 m. The piles exhibit a pull-up effect. The soil below the elevation of $-2.0 \mathrm{~m}$ is grouted and reinforced, and the second excavation is conducted. The location of the second excavation reaches the design of the main groove bottom elevation (approximately $-2.0 \mathrm{~m}$ elevation). The reinforced concrete 
cover is poured on top of the cast-in-place pile, and the cast-in-place pile is consolidated with the cover to reduce bulge deformation. A typical section of the subway is shown in Figure 3.

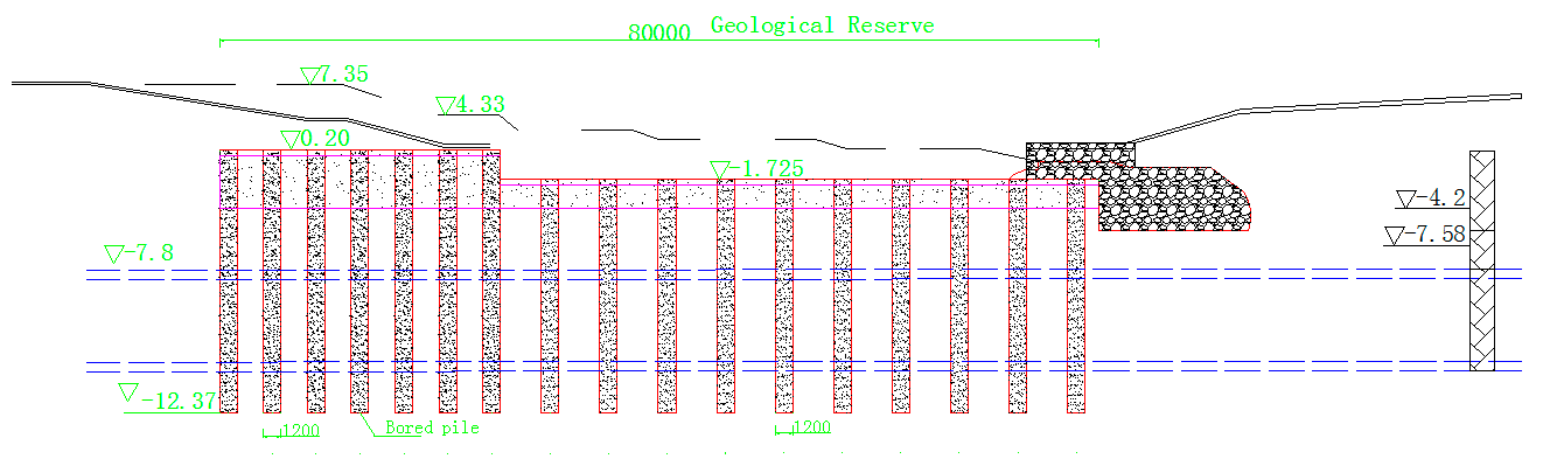

(a)

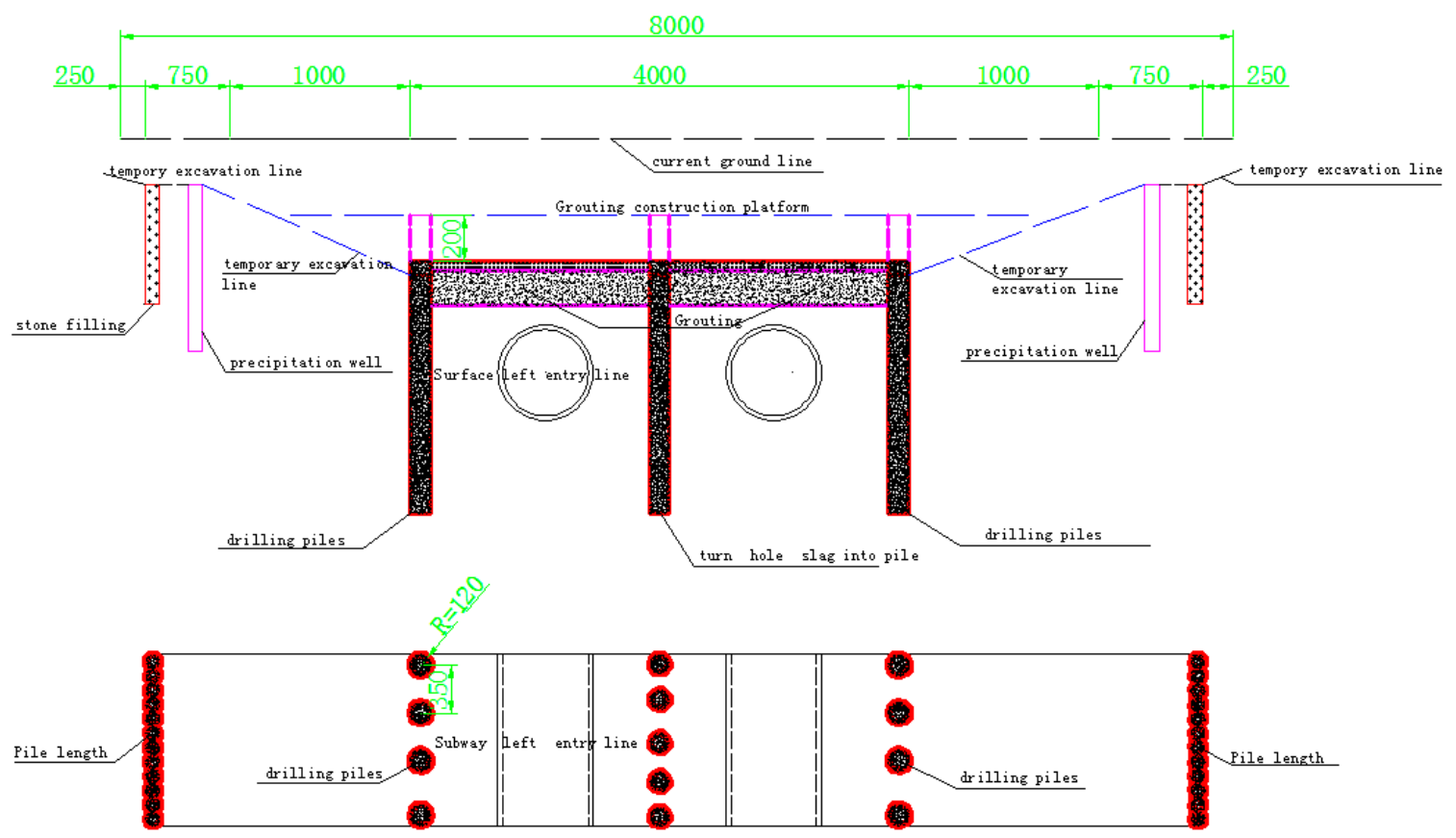

(b)

Figure 3. Typical cross-section form. (a) Longitudinal section of the subway vertical cross-section protection scheme; (b) Cross-section of the subway intersecting the fork section excavation area protection.

\section{Numerical Simulation}

\subsection{Numerical Simulation Program}

The numerical analysis software used was ABAQUS, an international large-scale finite element analysis software. ABAQUS simulated the water gallery of the right parking and exit intersection areas of the Qianhai parking lot. The left and right exits are mainly the cross-sections of different forms. The left side of the parking lot is a circular cross-section, whereas the right side is a square cross-section. Therefore, the numerical simulation mainly investigates the protective effect of the metro tunnel anti-uplift protection measures on metro tunnels with different sections and their mechanisms.

The tunnel anti-uplift protection measures of the parking access lines are shown in Figures 4 and 5 . 


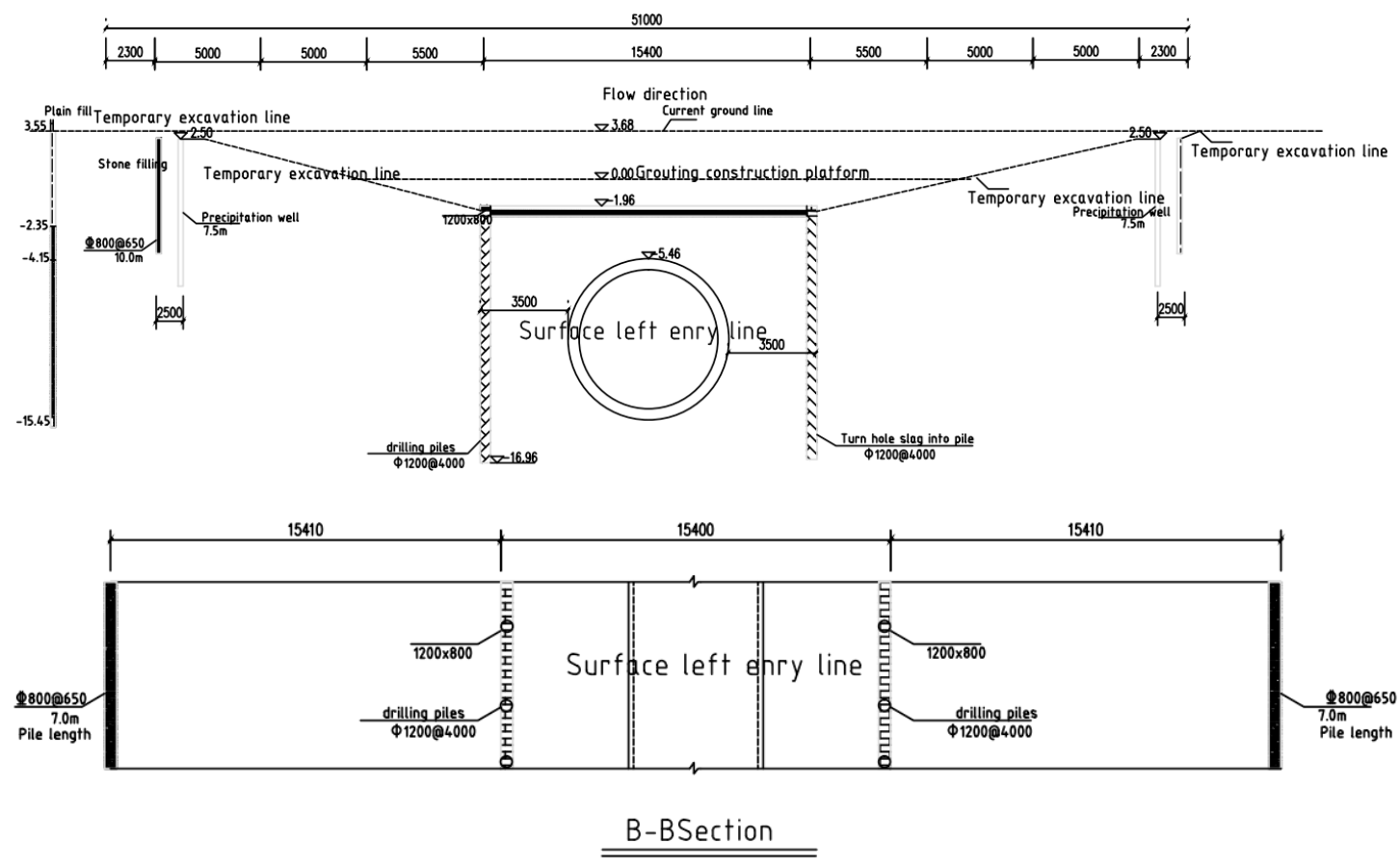

Figure 4. Anti-uplift protection measures for the left tunnel.



Figure 5. Anti-uplift protection measures for the right tunnel. 


\subsection{ABAQUS Numerical Model}

To analyze the influence of the water gallery construction on the safety performance of the existing subway tunnel under the designed protection scheme, the initial numerical simulation model considers the geological conditions of the tunnel in the Qianhai parking lot before excavation. In particular, the parking lot's entrance and exit were first simulated during the construction process, and then the construction of the water gallery was simulated.

In order to reduce the influence of the boundary effect, the model size needed to be extended to the tunnel boundary size. According to the principle of numerical analysis and general processing experience, the influence range of the foundation pit excavation in the horizontal direction was $3 \sim 5$ times the excavation depth, and the influence range in the vertical direction was $2 \sim 4$ times the excavation depth. In order to study the influence of foundation pit excavation on tunnel structure and reduce the boundary effect, the length, width and height of the model were set to $110 \mathrm{~m}, 60 \mathrm{~m}$ and $50 \mathrm{~m}$, respectively.

The vertical direction of the model was constrained for horizontal displacement. The bottom surface was constrained for displacement in three directions, and the upper surface boundary was free. The strata distributed in the calculation model were mainly fill layer, silt, stone filling and weathered granite. As for the finite element mesh division, the mesh was related to the calculation accuracy. However, a dense grid will increase the computing time, and the cells should be divided reasonably. The total number of model units established was 96,885 . The intersection models of the Qianhai parking tunnel and water gallery are shown in Figures 6 and 7.

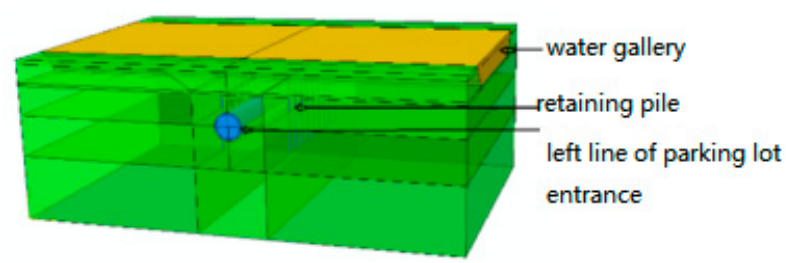

Figure 6. Overall diagram of the left tunnel and the water gallery model.

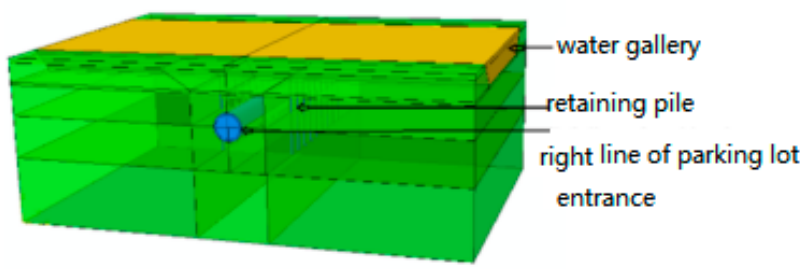

Figure 7. Overall map of the right line of the tunnel and the water gallery model.

\subsection{Numerical Simulation Analysis Steps}

The numerical simulation analysis was basically the same as the actual construction procedure. The specific analysis steps are listed in Table 1. 
Table 1. Numerical simulation analysis steps.

\begin{tabular}{cll}
\hline Step & \multicolumn{1}{c}{ Construction Content } & \multicolumn{1}{c}{ Remarks } \\
\hline 1 & Earth stress balance & $\begin{array}{l}\text { Geostress balance in the underground tunnel } \\
\text { without excavation }\end{array}$ \\
\hline 2 & Subway tunnel excavation and support & $\begin{array}{l}\text { The support structure is constructed when } \\
\text { the surrounding rock stress is } 40 \% .\end{array}$ \\
\hline 3 & Surface soil excavation & Grading angle of 1:1.5 \\
\hline 4 & Grading excavation of tunnel upper soil & \\
\hline 5 & Construction covers and uplift piles \\
\hline & $\begin{array}{l}\text { Subway tunnel excavation on both sides of } \\
\text { the upper soil }\end{array}$ & \\
\hline
\end{tabular}

\subsection{Material Parameters}

In the numerical simulation, the Mohr-Coulomb model was used for rocks and soil, whereas the elastic model was adopted for the support of uplift piles, cover plates, and subway tunnels. The specific parameter values are provided in Table 2.

Table 2. Material parameters.

\begin{tabular}{|c|c|c|c|c|c|}
\hline Category & $\begin{array}{l}\text { Bulk Weight } \\
\left(\mathrm{kN} / \mathrm{m}^{3}\right)\end{array}$ & $\begin{array}{c}\text { Formation } \\
\text { Modulus E (MPa) }\end{array}$ & $\begin{array}{l}\text { Poisson's } \\
\text { Ratio } \mu\end{array}$ & $\begin{array}{l}\text { Cohesion } \\
\text { (MPa) }\end{array}$ & $\begin{array}{c}\text { Friction } \\
\text { Angle } \psi\left({ }^{\circ}\right)\end{array}$ \\
\hline Fill layer & 18.7 & 13.5 & 0.30 & 0.1 & 16 \\
\hline Silt & 17 & 10 & 0.4 & 0.09 & 6 \\
\hline Stone filling & 22 & $3 e^{4}$ & 0.15 & 0 & 35 \\
\hline Weathered granite & 19.8 & $1 e^{5}$ & 0.2 & 1 & 30 \\
\hline $\begin{array}{l}\text { Anti-pull pile, cover, and } \\
\text { subway tunnel support }\end{array}$ & 25 & $3.45 \mathrm{e}^{4}$ & 0.17 & - & - \\
\hline
\end{tabular}

\section{Analysis of Results}

The vertical deformation of the subway tunnel of the parking access line and water gallery after construction was completed is shown in Figure 8.

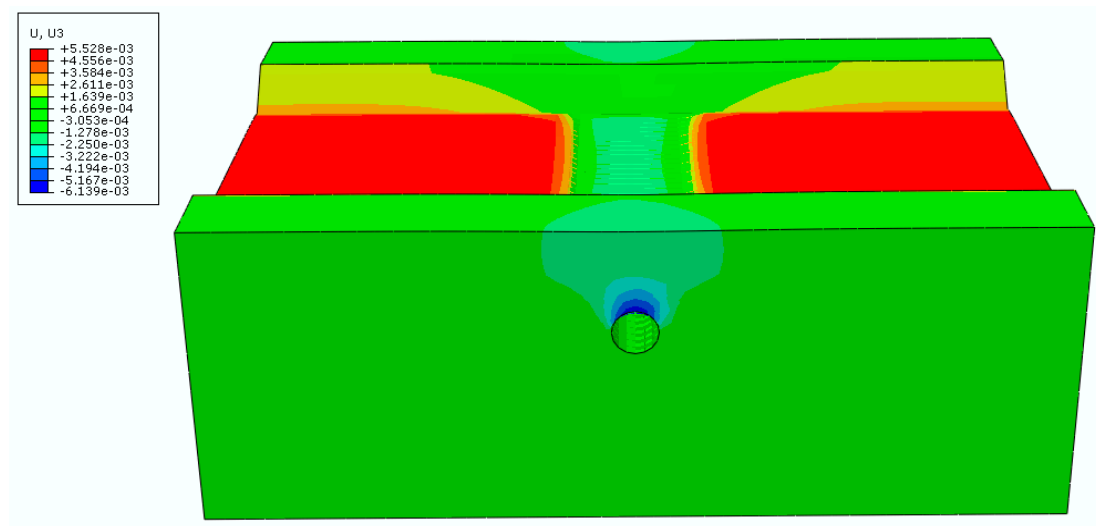

(a)

Figure 8. Cont. 

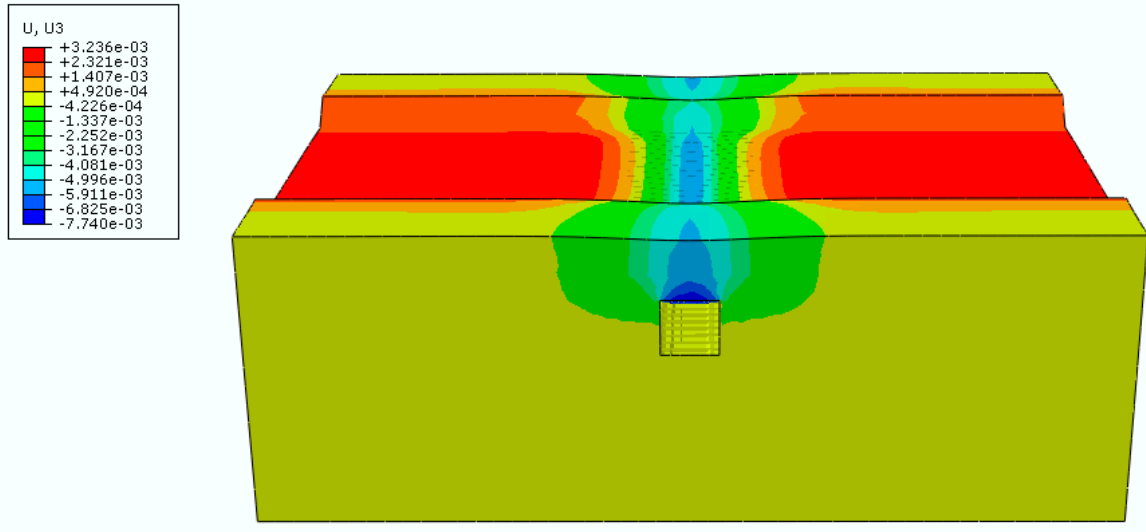

(b)

Figure 8. Vertical deformation cloud. (a) Left line tunnel; (b) Right line tunnel.

To investigate the protective effect of the anti-uplift protection measures for the subway tunnels on the cross-sections of different subway tunnels, the stress and strain of the cover and maintenance piles were analyzed separately. The amount of dome bump in the subway tunnel was analyzed comparatively to obtain the difference between the two sections.

\subsection{Covered Plate}

The cover, which uses reinforced concrete material for subway tunnel protection, has a thickness of $600 \mathrm{~mm}$. The left lane of the parking lot was $2.83 \mathrm{~m}$ from the underside of the reinforced concrete deck. The right tunnel dome was $3.43 \mathrm{~m}$ from the underside of the deck. To analyze the cover deformation, three typical cross-sections of the cover were used, as shown in Figure 9. The deformation curves of the three sections of the upper tunnel cover are shown in Figures 10 and 11.

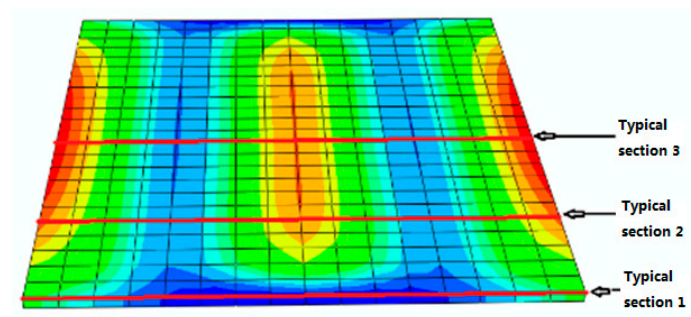

Figure 9. Typical sections of the cover.

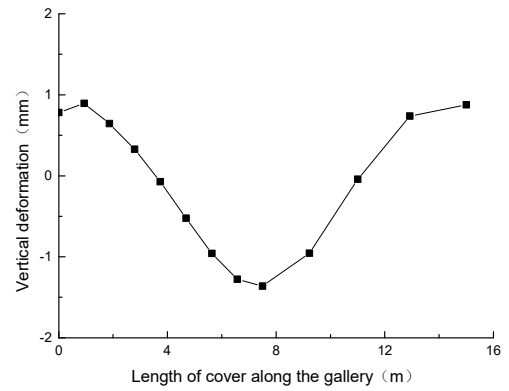

(a)

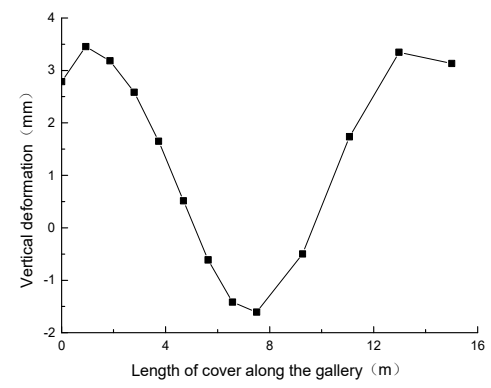

(b)



(c)

Figure 10. Deformation curve of the left subway line. (a) Section 1; (b) Section 2; (c) Section 3. 


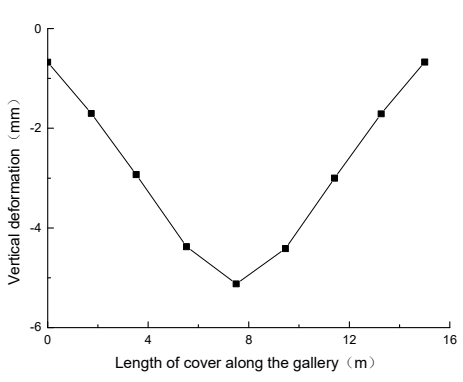

(a)



(b)

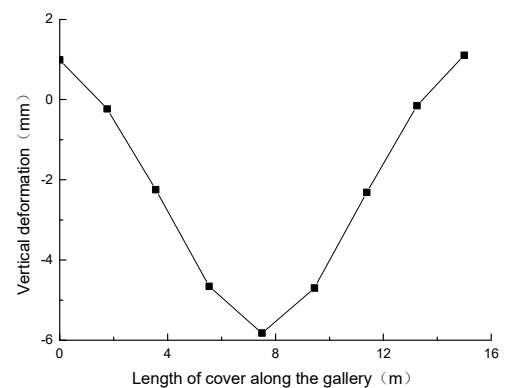

(c)

Figure 11. Deformation curve of the right subway line. (a) Section 1; (b) Section 2; (c) Section 3.

As shown in Figure 10, bumps appeared on both sides of Section 1 of the upper left circular cross-section of the tunnel. The maximum bump size was $1 \mathrm{~mm}$. Subsidence occurred in the middle section and the maximum settlement was $1.45 \mathrm{~mm}$. Section 2 also increased on both sides, with a maximum value of $3.45 \mathrm{~mm}$. Subsidence occurred in the middle section, and the maximum value was $1.65 \mathrm{~mm}$. The deformations of Sections 2 and 3 were basically similar. The maximum uplift was $3.5 \mathrm{~mm}$, and the maximum settlement was $1.75 \mathrm{~mm}$. Section 1 is under control due to the soil being restrained along the banks of the water gallery. Therefore, the deformation amount was relatively smaller than that of Sections 2 and 3. In addition, the maintenance of the two sides of the cover limits the bulge in the cover deformation and passes its own shear force to the cover. The cover is subjected to an axial force, and the final forms of stress are axial force (pressure), shear force, and the bending moment. In the initial stage, the retaining pile suffered from vertical upward deformation, during which both sides of the cover plate were tilted. Simultaneously, axial pressure was applied, during which the middle part of the cover plate was deflected downward to cause vertical downward deformation. This deformation exhibited good resistance to the bulge of the dome of the subway tunnel to a certain extent and prevented the excessive bulge deformation of the dome.

As shown in Figure 11, Section 1 had a vertical downward deformation on the upper cover of the right-angled, square section subway tunnel. The vertical deformation of the two sides was $0.6 \mathrm{~mm}$, and the middle deformation was the largest at $5.1 \mathrm{~mm}$. The two sides of Section 2 present an uplift deformation. The maximum uplift was $1.1 \mathrm{~mm}$, the middle section had a settlement deformation, and the maximum settlement was $5.85 \mathrm{~mm}$. Sections 2 and 3 had the same deformation curve. Section 1 was located at the junction of the cover plate and water gallery slope. The position of the cover plate and the excavation of the soil above it caused the slope of the water gallery bank to sink downward. The lower part of the cover tended to form a vertical bulge. The two sides of Section 1 subsided slightly due to the constraint of this section and the bank slope. Compared with the left circular tunnel of the parking lot, the uplift of the upper cover of the right square tunnel was relatively small and its settlement was relatively large. Thus, the capacity of the square section of the subway tunnel to accommodate the upper load was considerably weaker than that of the circular tunnel.

\subsection{Retaining Pile}

The length of the retaining pile on both sides of the tunnel was $16 \mathrm{~m}$, and was a circular section with a diameter of $1.2 \mathrm{~m}$. The deformation maps of the retaining pile in three directions after the excavation of the water gallery was completed are shown in Figures 12 and 13. The shear cloud of the retaining pile is shown in Figure 14. The shear force curve of a typical retaining pile with depth is shown in Figure 15. 

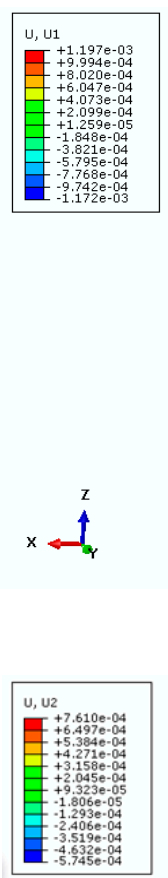

$\times \stackrel{z}{z}$

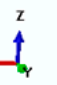
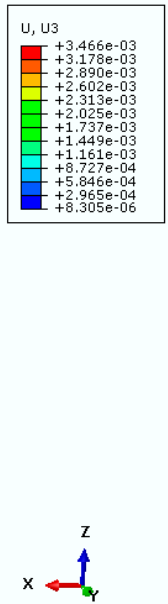
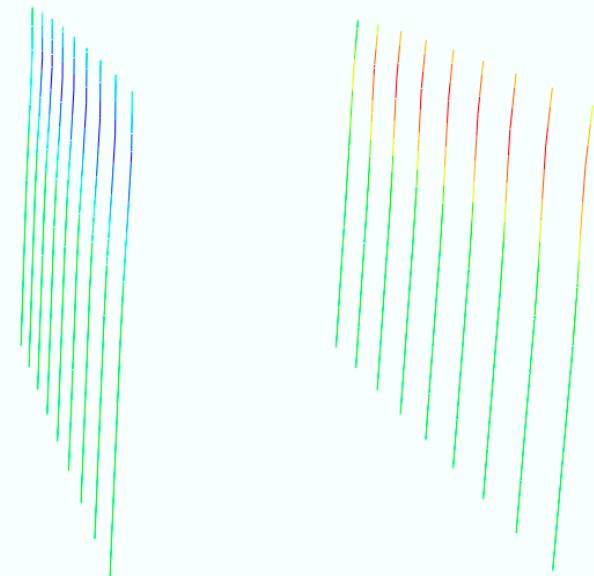

(a)
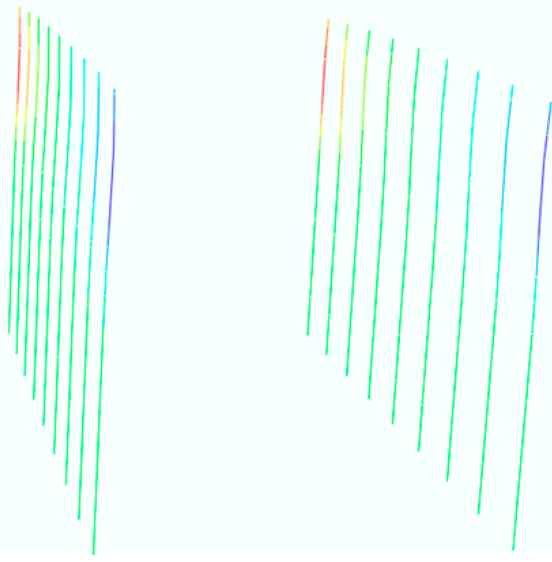

(b)
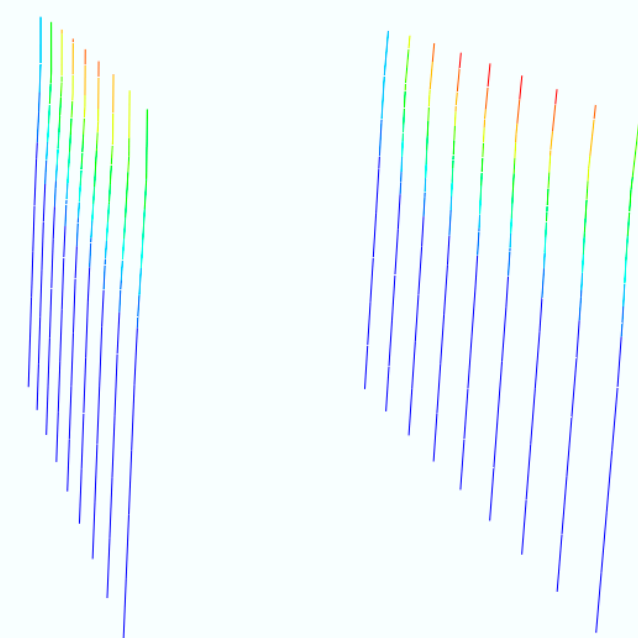

(c)

Figure 12. Deformation cloud of the left retaining pile. (a) $x$ direction; (b) $y$ direction; (c) $z$ direction. 

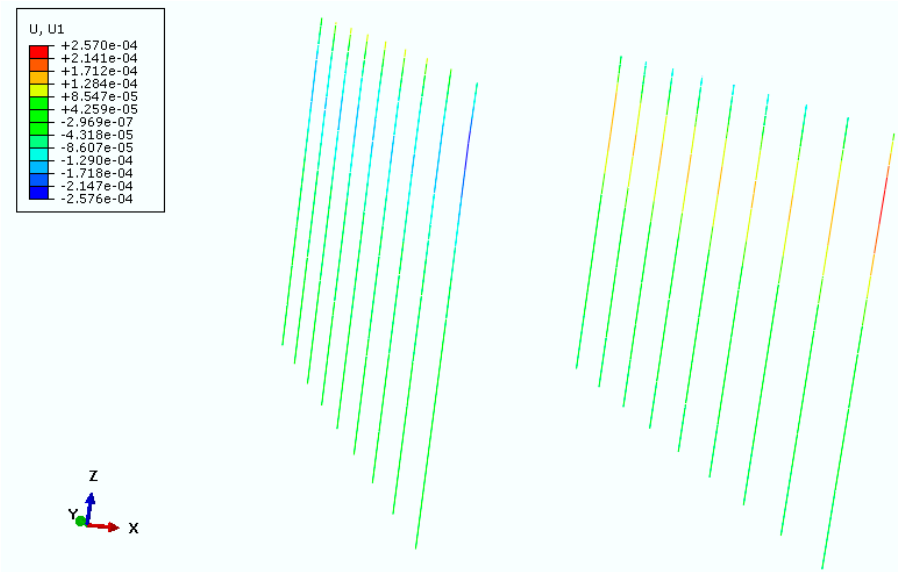

(a)
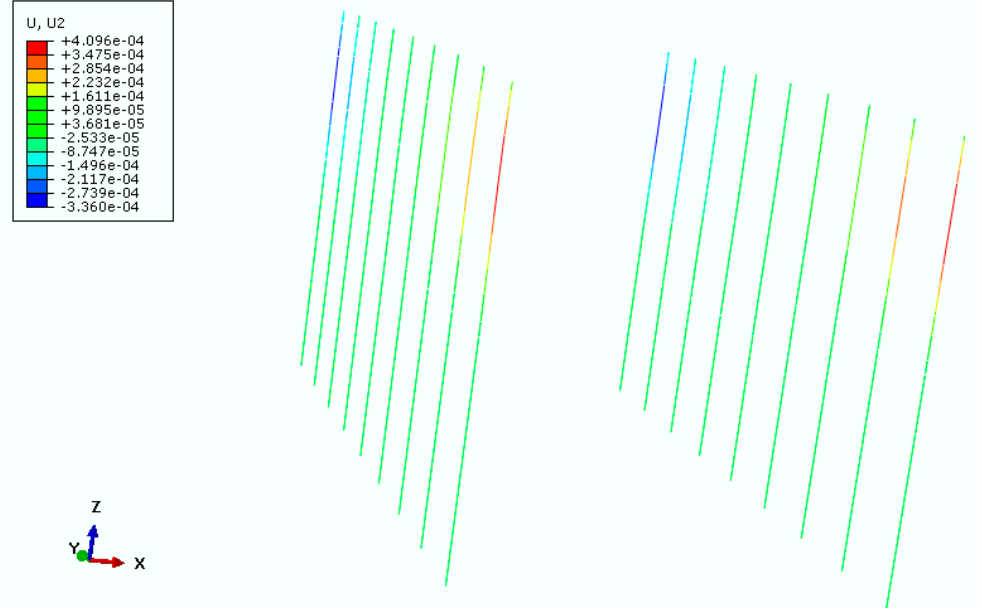

(b)
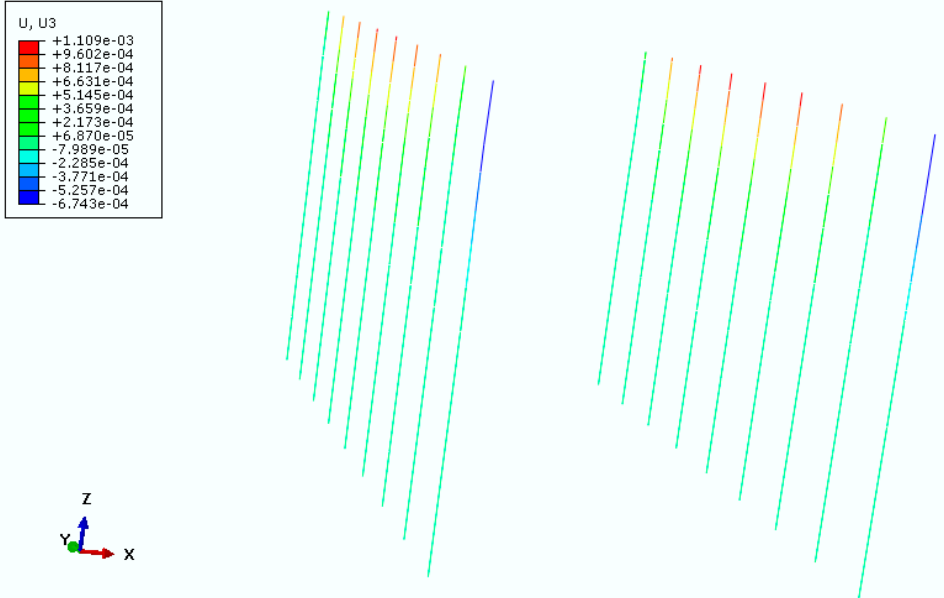

(c)

Figure 13. Deformation cloud of the right retaining pile. (a) $x$ direction; (b) $y$ direction; (c) $z$ direction.

As shown in Figures 14 and 15, the maximum deformation of the retaining pile in the $x$ direction on both sides of the left line was $1.2 \mathrm{~mm}$, and the direction was a vertical tunnel. The maximum deformation of the retaining pile on both sides of the right line in the $x$ direction was $0.26 \mathrm{~mm}$. The direction was from the tunnel to both sides of the radiation, which is contrary to the deformation 
direction of the circular tunnel retaining pile. As shown in Figure 15, the combination of the upper cover of the square tunnel and the retaining pile provided the stress value to the retaining pile via the Earth's pressure in the upper part of the tunnel dome, which was smaller than that of the circular tunnel. The maximum deformation of the retaining pile on both sides of the left circular subway tunnel in the $y$ direction was $0.76 \mathrm{~mm}$, and the direction was from the middle of the water gallery to both sides of the water gallery. The maximum deformation of the retaining pile in the $y$ direction on both sides of the right line was $0.41 \mathrm{~mm}$, and the direction was from the middle point of the water gallery to both sides of the water gallery. The maximum deformation of the retaining pile on both sides of the left tunnel in the $z$ direction was $3.5 \mathrm{~mm}$, and the direction was vertically upward. The maximum deformation of the retaining pile on both sides of the right tunnel in the $z$ direction was $1.1 \mathrm{~mm}$, and the direction was also vertically upward. The displacement of the retaining pile of the left lane tunnel was larger than that of the right lane, thereby indicating that the upper cover of the square tunnel was working efficiently.
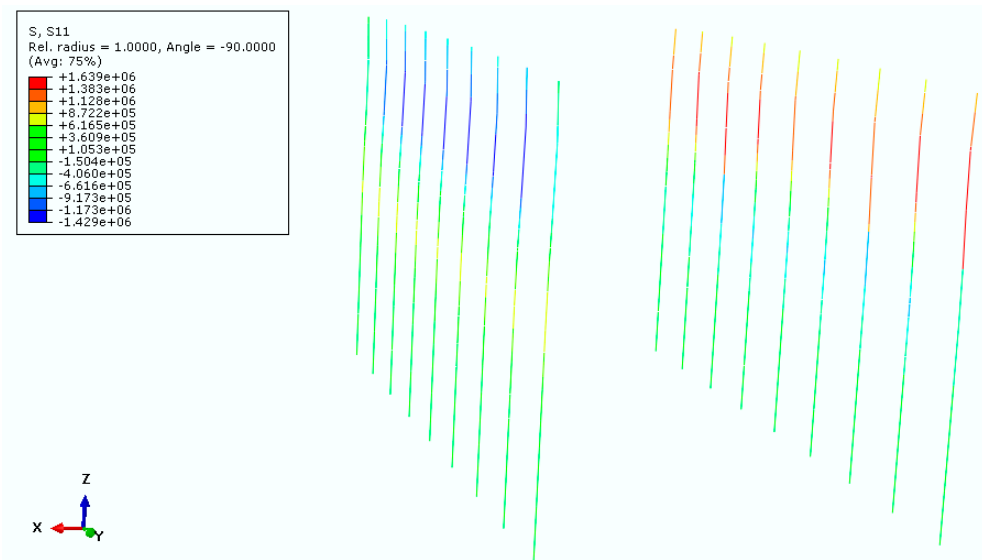

(a)
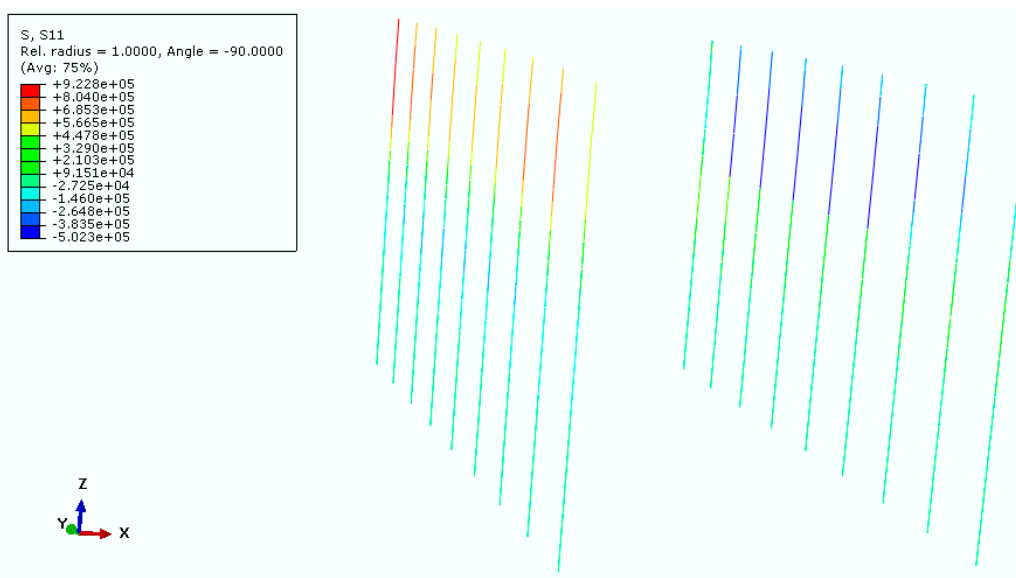

(b)

Figure 14. Shear shield cloud. (a) Left line tunnel; (b) Right line tunnel.

As shown in Figures 14 and 15, the maximum shear force value of the retaining pile on both sides of the left circular cross-section subway tunnel was $1.35 \mathrm{MPa}$ and appeared at a position approximately $1 \mathrm{~m}$ above the tunnel dome. Two evident cases of shear force sign mutation were observed. The mutation location depended on the center of the circular section, and the maximum value after the mutation depended on the bottom of the circular section. The maximum shear value of the retaining pile on both sides of the right tunnel was $0.49 \mathrm{MPa}$, and the maximum value appeared in the position where the direction tunnel vault was located. A clear two-value shear force sign mutation 
was observed on the right line, for which the first mutation was located at the level of the square tunnel center. When the curves of the shear forces on the two sides of the two retaining sections were compared, the shear force of the retaining columns beside the square tunnel was found to be considerably smaller than that of the circular tunnel. The maximum shear value of the retaining pile on both sides of the square tunnel was $36.3 \%$. Therefore, the existing protective measures were safer and more suitable for square tunnels than for circular tunnels, in terms of the shearing force of the retaining pile.

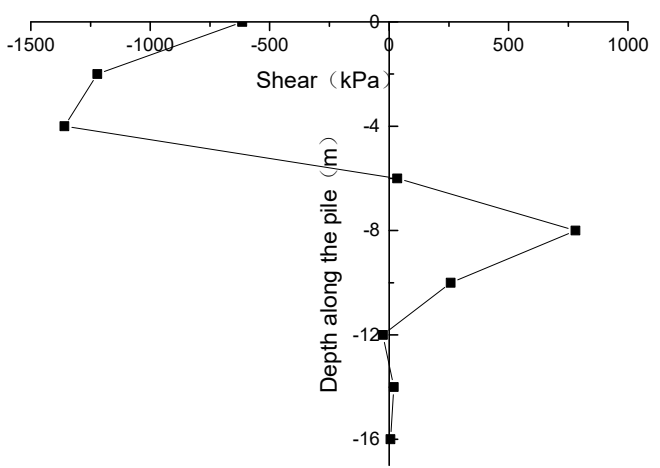

(a) Left line tunnel

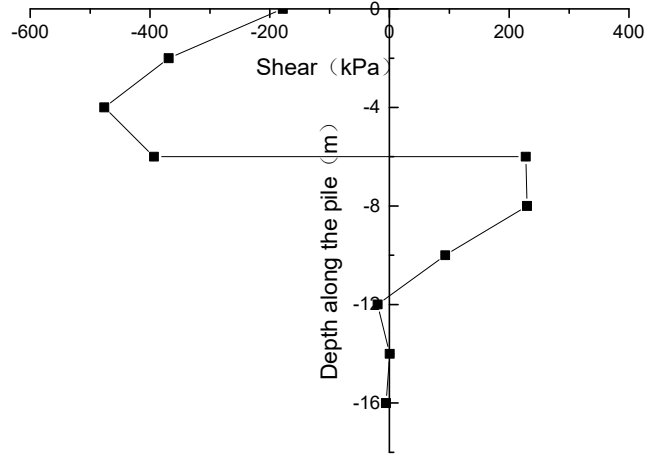

(b) Left line tunnel

Figure 15. Shear curve of the fender post. (a)Left line tunnel; (b) Left line tunnel.

\subsection{Subway Tunnel Vault}

Figure 16 presents the vertical deformation curve of the subway tunnel vault along the tunnel under the influence of the water gallery construction. As shown in the figure, the maximum uplift of the arch of the left circular tunnel was $0.029 \mathrm{~mm}$, and was located at the intersection of the water gallery shore and the left tunnel. The middle position had an evident straight section, and the length of the straight section was the same as the length of the cover plate. The minimum bulge in the straight section was $0.025 \mathrm{~mm}$. This condition shows evident inhibition of the tunnel vault cover. The maximum uplift of the right tunnel vault was $0.05 \mathrm{~mm}$, this was also located at the intersection of the water gallery bank and the left tunnel. An evident concave section was observed in the reinforced concrete cover position. The minimum amount of bulge in the middle of the square tunnel was $0.005 \mathrm{~mm}$, which is considerably lower than the minimum bulge of the straight section of the circular tunnel. This shows that the inhibition of the reinforced concrete cover of the square tunnel uplift was better than that of the circular tunnel. This finding is attributed to the fact that the shape of the cover was the same as that of the square tunnel, and that the force synergy was better than that of the circular tunnel. In addition, the crown of the square tunnel vault that covered the edge location of the uplift was considerably larger than that of the circular tunnel. Therefore, the cover plate should be embedded into the interior of both sides of the water gallery to ensure the anti-raising effect of the cover plate and retaining pile in the actual engineering design and construction. 


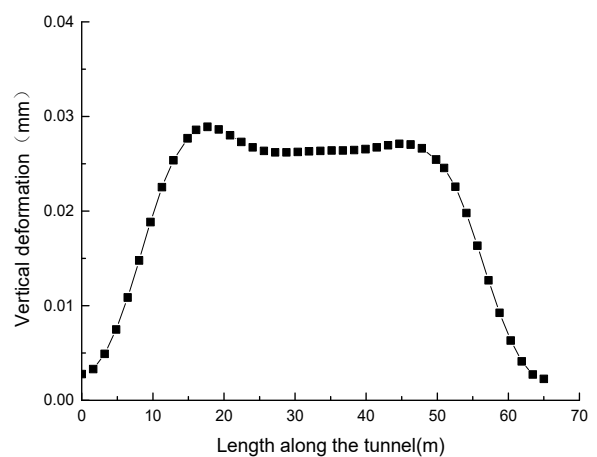

(a)

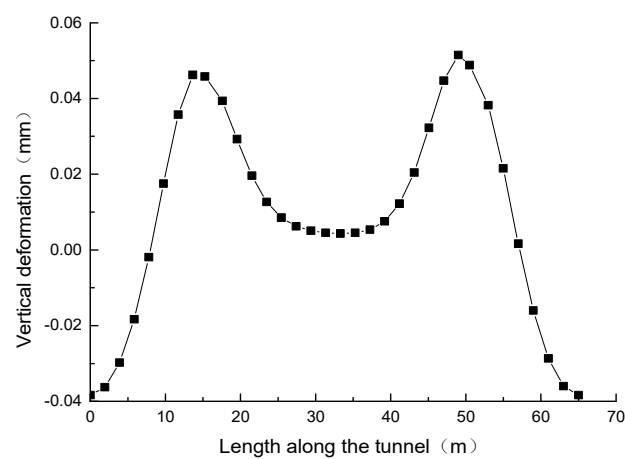

(b)

Figure 16. Vertical deformation of the vault. (a) Left line tunnel vault; (b) Right line tunnel vault.

\section{Conclusions}

(1) In the upper part of the subway tunnel, the cover, which serves as the anti-uplift protection measure of the tunnel, should withstand axial pressure, shear force, and the bending moment. Under the combined action of these forces, warping deformation occurred on both sides of the cover plate, and vertical downward deformation occurred in the middle section. The vertical deformation on the upper deck of the square section tunnel was larger than that of the circular tunnel.

(2) Retaining piles, which are part of the anti-uplift protection system for metro tunnels, resist pull and are able to bear shear forces. The shear strength values of the retaining piles on both sides of the circular and square tunnels exhibited two evident sign mutations, and their maximum shear values were all located near the horizontal plane where the tunnel vault was located. In addition, the maximum shear force of the retaining pile on both sides of the square tunnel was considerably smaller (by $36.3 \%$ ) than that of the circular tunnel retaining pile.

(3) The protective effect of the current anti-uplift protection system on the circular and square tunnel domes is evident. In addition, the vertical deformation curve of the subway tunnel dome showed that the circular tunnel had a straight segment and the square tunnel had a concave segment, thereby indicating that the current anti-uplift protection system had a better effect on the square tunnel than on the circular tunnel. A considerable amount of bulge was found on both sides of the cover, which suggests that the embedding length of the cover on both sides of the water gallery should be increased in the actual project.

Funding: This research received no external funding.

Conflicts of Interest: The authors declare no conflict of interest.

\section{References}

1. He, C.; Fan, K.; Fang, Y. Technical Status Quo and Prospects of Shield Tunneling in Subway Tunnel Construction. J. South West JiaoTong Univ. 2015, 50, 97-109.

2. Hu, Q.; Qin, J. Statistical Analysis of Subway Tunnel Construction Accidents in $2003-2011$. Acta CymbarSurgica Sin. 2013, 9, 705-710.

3. Hong, K. The status and prospect of tunnel and underground engineering in China. Tunn. Constr. 2015, 2, 95-107. [CrossRef]

4. Feedback Author Email Title Code Content Copyright. Rock Soil Mech. Acta Metall. Sin. 2009, 30, $269-272$.

5. Liu, B.; Tao, L.; Li, X.; Tang, M.-X. Study on deformation induced by subsoil shield tunnel under building foundation. Acta Sci. Sin. Sin. 2006, 2, 621-626.

6. Hua, J.-S.; Wang, B.-L.; Zhou, S.-H. Analysis of Reinforcement of Ground Reinforced Underpass Intercity Railway Shield Tunnel. China Railw. Sci. 2011, 32, 71-77.

7. She, C. Safety Measures for Subway Shield Tunnels Underpassing Railway. J. Urban Rail Transit 2009, 12, 33-36. 
8. Li, K.; Gao, B. Study on construction scheme of subway tunnel passing through small river and bridge. Rock Soil Mech. 2010, 31, 1509-1516.

9. Xu, Z.-M.; Han, Q.-H.; Zheng, G.; Zhang, L.-M. Simulation and analysis of the influence of metro tunnel construction under historical style. Chin. J. Geotech. Eng. 2013, 35, 364-374.

10. Wang, L.-Y.; Yang, Z.-Y. Construction Technology of Subway Tunnel Underpass Viaduct. Munic. Eng. Technol. 2010, 28, 101-103.

11. Ran, S.; Zhou, J.; Li, Y. Impact of Next-Construction of Underpass Buildings in Guangzhou Metro Tunnel. Low Temp. Build. Technol. 2007, 1, 58-60; [CrossRef]

12. Tan, F. Subway tunnel under the expansion of the basic bridge construction analysis. Railw. Stand. Des. 2009, 10, 100-102. [CrossRef]

13. He, C.; Su, Z.; Zeng, D. Effects of Overlapped Metro Shield Tunnel Construction on the Built Tunnel Above. Chin. J. Civ. Eng. 2008, 41, 91-98.

14. He, W.-Q.; Li, T.-K.; Huang, J.-B. A comparison analysis and economic analysis of the structure of a subway superstructure. Sci. Arch. 2016, 32, 113-117.

15. Xu, Y.-J.; Nie, X.-L.; Wei, Y.-J.; Yin, Y.-Z.; Bao, X.-K. Deformation control of the existing metro structures worn by new metro stations. Acta Sinolica Sin. 2016, 12, 153-161.

16. Zhu, J. Analysis of the Influence of the Steel Structure Building of the Subway Entrance and Exit Cover. Chin. J. Undergr. Space Eng. 2003, 10, 1823-1828.

17. Das, R.; Singh, P.K.; Kainthola, A. Numerical analysis of surface subsidence in asymmetric parallel highway tunnels. J. Rock Mech. Geotech. Eng. 2017, 9, 170-179. [CrossRef]

18. Wan, L.; Song, Z.; Qu, J. Analysis of construction techniques for a metro tunnel approaching an existing station. Mod. Tunn. Technol. 2015, 52, 168-176.

19. Fang, Y.; Xu, C.; Cui, G. Scale model test of highway tunnel construction underlying mined-out thin coal seam. Tunn. Undergr. Space Technol. 2016, 56, 105-116. [CrossRef]

(C) 2018 by the author. Licensee MDPI, Basel, Switzerland. This article is an open access article distributed under the terms and conditions of the Creative Commons Attribution (CC BY) license (http://creativecommons.org/licenses/by/4.0/). 